\title{
Failure of pulmonary artery banding due to migration of the band
}

\author{
D. VEREL, D. G. TA Y L OR, J . L . E M ER Y \\ Sheffield Cardiothoracic Unit, Northern General Hospital, Sheffield S5 7AU, and the \\ sheffield Children's Hospital
}

\begin{abstract}
Pulmonary artery banding controlled the distal pulmonary artery pressure at operation in a 16-month old infant. When she was reinvestigated over two years later there was no pressure gradient at the site of the band. At operation the band was found to have migrated into the lumen of the artery.
\end{abstract}

The value of pulmonary artery banding in relieving symptoms due to large left-to-right shunts in infants has been established by a number of authors (Thompson, Muller, and Dammann, 1958 ; Dammann, McEachen, Thompson, Smith, and Muller, 1961 ; Therkelsen, Gammelgaard, and Boesen, 1959 ; Smith and McEachen, 1960 ; Morrow and Braunwald, 1961 ; Willman, Cooper, Mudd, and Hanlon, 1962; Ochsner, Cooley, McNamara, and Kline, 1962 ; Craig and Sirak, 1963 ; Goldblatt, Bernhard, Nadas, and Gross, 1965).

In a report of our experience of this procedure (Grainger, Nagle, Pawidapha, Robertson, Taylor, Thornton, Verel, and Zachary, 1967), two patients were found at post-operative catheterization to have hypertensive lungs after apparently satisfactory pulmonary artery banding. The subsequent course of one of these infants is reported in this paper.

\section{CASE REPORT}

The child was a girl who had failed to thrive following a normal delivery. She was subject to recurrent attacks of 'pneumonia'.

She was referred to out-patients on 20 October 1961 aged 15 months with a history of recurrent chest infections. Her nutrition was good (weight $21 \mathrm{lb}$. (9.5 kg.), birth weight $7 \mathrm{lb}$. $(3 \cdot 1 \mathrm{~kg}$.) ). The heart was clinically enlarged with a marked lift over the pulmonary outflow, a palpable pulmonary second sound, a loud precordial systolic murmur, and a soft early diastolic murmur near the apex. In view of her pulmonary symptoms, which persisted despite chemotherapy, she was admitted and cardiac catheterization was performed on 9 January 1962. A pressure of $85 / 0 \mathrm{~mm} . \mathrm{Hg}$ was found in the right ventricle with a left-to-right shunt of 3.5:1 (Grainger et al. (1967), Table II, case 10).

Pulmonary artery banding was undertaken one month after cardiac catheterization and was unremarkable. A patent ductus of moderate size was tied at the time of the banding. Following operation the child's progress was disappointing, she gained weight and height slowly, and remained somewhat short of breath with intermittent heart failure. Eventually two years and nine months after the initial catheterization the patient was reinvestigated. A pulmonary artery pressure of $80 / 30 \mathrm{~mm}$. $\mathrm{Hg}$ and a right ventricular pressure of $80 / 0 \mathrm{~mm}$. $\mathrm{Hg}$ were found, the shunt remaining at $3 \cdot 5: 1$, left to right. No gradient was found at the site of the band. Cine angiography was used on this second occasion and the detail obtained was not sufficient to permit an opinion as to the state of the pulmonary artery band. Intermittent cyanosis on exercise was observed as the child grew older, and eventually it was decided to attempt primary closure of the ventricular septal defect in view of her gradual deterioration.

Thoracotomy was performed at the age of $5 \frac{1}{2}$ years.

The external appearances were consistent with a large left-to-right shunt with a huge right ventricle and a pulmonary artery diameter of $3 \mathrm{~cm}$. Digital exploration from the right atrium confirmed a large ventricular septal defect, approximately $1.5 \mathrm{~cm}$. in diameter, in a high position immediately under the aortic ring. This was associated with a cleft tricuspid valve, and it was felt that exposure sufficiently satisfactory for repair could be achieved through an atrial approach. Under total bypass the defect was closed with horizontal mattress sutures buttressed above and below by strips of pericardium. The area of the previous banding was then examined. The band was approximately $1 \mathrm{~cm}$. above the valve ring. When the pulmonary artery was incised longitudinally it was found that the band consisted of an endothelialized 

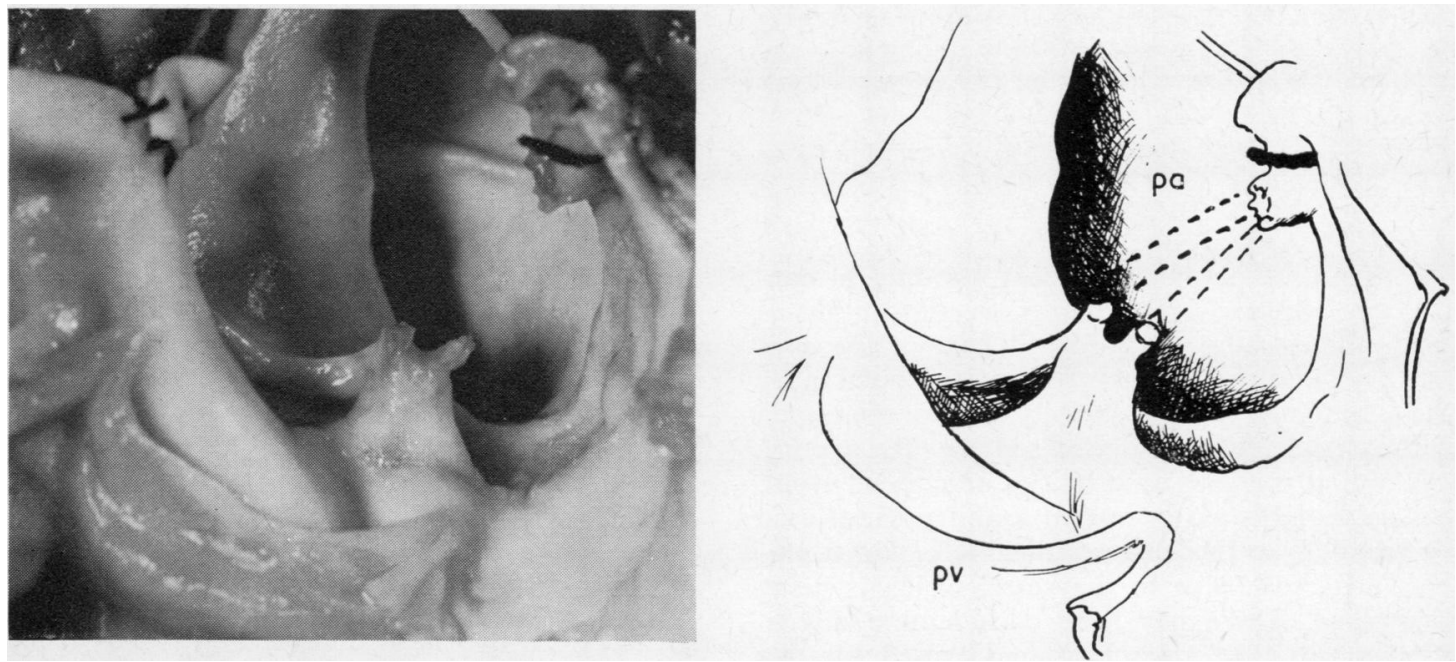

FIG. 1. Photograph looking upwards into the pulmonary artery ( $p a)$ through the pulmonary valve (pv), showing the site of the initial banding suture traversing the completely re-canalized pulmonary artery.
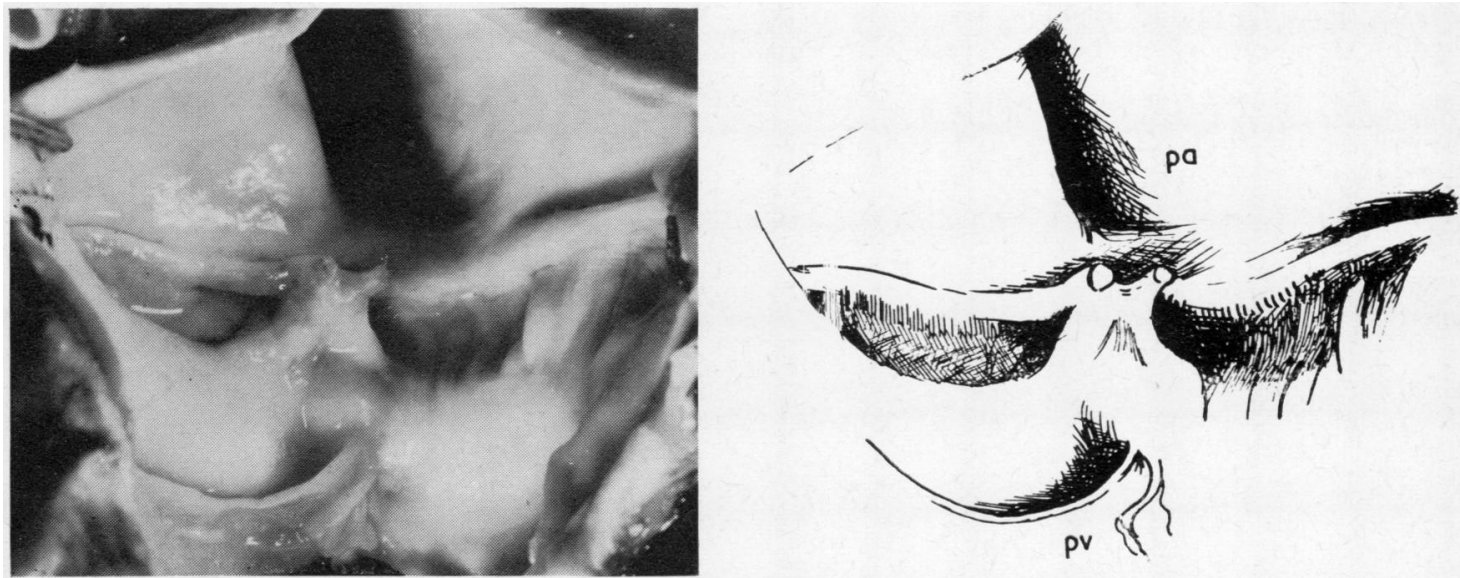

FIG. 2. Photograph looking into the area of the band and showing sacculation and thinning of the wall of the pulmonary artery (pa) immediately proximal to the suture. The suture tissue has traversed the arterial wall at this point.

cord extended across the lumen of the pulmonary artery. It was removed and the arteriotomy was closed. The pulmonary valve was normal.

Routine closure and elective tracheostomy were uneventful. Shortly before leaving the theatre heart block occurred. Satisfactory pacing was achieved after an episode of ventricular fibrillation. However, the heart proved unable to maintain an adequate circulation and the patient died some hours after operation.

At necropsy there was evidence of cardiac failure with serous effusions of $500 \mathrm{ml}$. in a peritoneal cavity and $300 \mathrm{ml}$. in each pleural cavity. The lungs showed no evidence of pneumonia.

The right ventricle was considerably thickened and dilated leading up to a normal pulmonary valve. Approximately $1 \mathrm{~cm}$. above the valve there was an area of partial dilatation and immediately beyond this point small conical masses of tissue projected into the lumen (Figs 1 and 2). These had been partially removed at operation and it was obvious that there had been a previous string-like mass crossing the pulmonary artery and converting it into two distinct 
cavities. The pulmonary artery showed no thickening but was considerably dilated. Both the mitral and tricuspid valves were distorted by fibroelastosis. Sections of pulmonary artery and projecting masses showed suture material surrounded by dense collagen.

\section{DISCUSSION}

The failure of pulmonary artery banding to control the pressure in the lungs in this infant is clearly due to the migration of part of the constricting band through the wall of the pulmonary artery so that it came ultimately to lie in the lumen of the vessel like an isolated septum. We are unable to find previous descriptions of such an event. It is presumably partly related to the material used for banding, in this case stranded silk, which presents a narrow edge to the vessel which is being constricted. There has been considerable discussion on the most suitable material used for this operation. The event we describe here provides another argument against the use of a narrow silk cord for the purpose.

The infant's age at the time of operation is a further possible factor. Banding was done at the age of 16 months when the great vessels are rela- tively large. We do not now attempt pulmonary artery banding in infants of this age.

\section{REFERENCES}

Craig, T. V., and Sirak, H. D. (1963). Pulmonary artery banding. An analysis of 38 cases. J. thorac. cardiovasc. Surg., 45, 599.

Dammann, J. F., McEachen, J. A., Thompson, W. M., Jr., Smith, R., and Muller, W. H., Jr. (1961). The regression of pulmonary vascular disease after the creation of pulmonary stenosis. Ibid., 42, 722.

Goldblatt, A., Bernhard, W. F., Nadas, A. S., and Gross, E. R. (1965). Pulmonary artery banding. Indications and results in infants and children. Circulation, 32, 172.

Grainger, R. G., Nagle, R. E., Pawidapha, C., Robertson, D. S., Taylor, D. G., Thornton, J. A., Verel, D., and Zachary, B. R. (1967). Pulmonary artery banding for ventricular septal defect. Brit. Heart J., 29, 289.

Morrow, A. G., and Braunwald, N. S. (1961). The surgical treatment of ventricular septal defect in infancy. Circulation, 24, 34.

Ochsner, J. L., Cooley, D. A., McNamara, D. G., and Kline, A. (1962). Surgical treatment of cardiovascular anomalies in 300 infants younger than one year of age. J. thorac. cardiovasc. Surg., 43, 182.

Smith, R. T., and McEachen, J. A. (1960). Evaluation of the Dammann-Muller procedure for large left-to-right shunts in infancy. Surg. Forum, 11, 254.

Therkelsen, F. Gammelgaard, P. A., and Boesen, I. (1959). Ventricular septal defects in infants treated with various modifications of the Dammann-Muller operation. Acta chir. scand., Suppl. 245 , p. 249.

Thompson, W. M., Jr., Muller, W. H., Jr., and Dammann, J. F., Jr. (1958). Analysis of clinical results from the surgical creation of pulmonary stenosis in thirty-five patients with large intrapulmonary stenosis in thirty-five pommunications (Abstract). Circulation, 18, 789.

Willman, V. L., Cooper, T., Mudd, J. G., and Hanlon, C. R. (1962) Treatment of ventricular septal defect by constriction of pulmonary artery. Arch. Surg., 85, 745. 